\title{
Employee Complacency and Corporate Demise
}

\section{Gary OSTER ${ }^{1}$}

\begin{abstract}
A significant problem afflicting many historically successful corporations is employee disengagement caused by complacency. Complacency is the self-satisfaction with the status quo that provides employees with feelings of quiet pleasure, security, and ease. It severely constrains life-giving corporate innovation and change, which are crucial to enterprise success in the volatile modern global economy. Complacency may lead to corporate dissolution if not intentionally reversed. This paper provides leaders with potential strategic changes that can combat complacency and promote actions necessary for positive strategic innovation.
\end{abstract}

"Success breeds complacency. Complacency breeds failure. Only the paranoid survive." Andy Grove, Intel Corporation

Keywords: corporate demise, corporate strategies, complacency

JEL classification: L10, L20, M10

DOI: $10.24818 /$ RMCI.2019.2.122

\section{Introduction}

Whether a one-person pretzel cart or a 100,000-person corporate giant, every modern enterprise functions within the constraints and opportunities of the uncertain global economy. Product life-cycles are attenuated as new products and services continually appear only to be replaced by newer, more attractive items. Hyperinformed customers utilize always-available social media reviews to choose, then abandon, the latest products and services (Hamel, 2002). The worldwide availability of free online information means that the next major competitor may be either a multi-national conglomerate or two young women working out of the local coffee shop. The modern economic environment features the ongoing convergence of industries (e.g. telephony, computers, and entertainment built into cellphones), relentless competition from previously unsubstantial backwater countries, limitations of natural and man-made resources, and the continued volatility of global financial markets.

1 Gary Oster, Regent University, 1000 Regent University Drive, Virginia Beach, garyost@regent.edu 


\section{The Pressure of Discontinuous Change}

Inconstant markets require that leaders develop and successfully implement corporate strategies amenable to the volatile worldwide marketplace. Failure to do so often results in corporate sudden death (Gryskiewicz, 1999). Leadership experts have noted that, "When the change in the environment is faster than the change inside your company, the end is in sight" Slater, 2004),"and, "Ignoring the inevitability of change can be fatal" (Gryskiewicz, 1999). Others have said, "Denial is tragic. Delay is deadly" (Hamel, 2002).

The centerpiece for surviving and thriving in the volatile environment is continuous innovation and positive change: "Out there in some garage is an entrepreneur who's forging a bullet with your company's name on it. You've got one option now - to shoot first. You've got to out-innovate the innovators" (Hamel, 2002). Similarly, "Superior innovation provides a company the opportunities to grow faster, better, and smarter than their competitors - and ultimately to influence the direction of their industry...In the long run, the only reliable security for any company is the ability to innovate better and longer than competitors" (Davila, et al., 2006).

Regardless of size or historical success, every organization is afflicted with entropy. Entropy, a term borrowed from biomechanics, means that things have a tendency to decline into disorder. Whether acknowledged or not, company change is inevitable: "Strategy decay is not something that might happen; it's something that is happening... every business model is decaying as we speak" (Hamel, 2002). Leadership attention to the changing environment and strategic needs is crucial. Herman Miller, Inc. CEO Max DePree describes his most important executive role as, "The interception of entropy...I choose to define it as meaning that everything has a tendency to deteriorate" (DePree, 2004). There are no static organizations. Every firm that has not successfully implemented an intentional growth strategy is already dying.

\section{The Hidden Dangers of Complacency}

Perhaps the most clandestine of all impediments to long-term corporate success is complacency. Complacency is the self-satisfaction with the status quo that provides employees with feelings of quiet pleasure, security, and ease. Complacency is most often prevalent in large, historically successful companies. Why would this be? Contented employees and leaders alike tend to equate a successful legacy with the likelihood of ongoing achievement, yet, historical success has no causal tie to future viability. Complacency and a "too big to fail" attitude blind organization members to the unrelenting need for positive change: "Organizations that have been very successful in their fields often find it most difficult to change. Even though their historic success may have been built on a highly innovative idea, there is a common tendency to calcification" (Gryskiewicz, 1999). While company officials say, "This is what got us to where we are today, so let's stick with it," rivals are 
quickly and quietly developing new products and services that will force incumbents from product leadership.

\section{Causes and Symptomology of Complacency}

One or more conditions may help disseminate complacency in an organization. Complacency is oftentimes encouraged by organization size, patents, industry orthodoxy, workforce rewards for allegiance to past practices, reliance on an internal focus, positive media support, government protection, strong internal politics, the prevalence of internal departmental or divisional silos, a lack of information sharing due to mechanism or desire, unrealistic disdain of current and potential competitors, the not-invented-here syndrome, or eagerness for a satisfied workforce or directorship.

There are many characteristics that identify a complacent company. However, a relatively small number of symptoms may be found in virtually all organizations impaired by complacency. Complacent companies are often recognized because of their myopic push for efficiency, strong centralization of decision-making, reliance on "gut feeling" and the intelligence of leaders, frequent reorganizations, absence of meaningful objective metrics, aspirational reporting, obvious lack of urgency, continuous planning without subsequent execution, installation of fear in and focus of blame on any employee who points out potential negatives, the regular introduction of ineffective and unprofitable products, the blooming of innovation antibodies, ignoring of external customers, and financially doubling-down on what hasn't worked. Senior leaders ("giants of the industry") are often in attendance at industry conferences, pontificating on their "secret sauce" of success.

\section{Dismal Outcomes of Complacency}

Why is complacency such an important issue when so many other problems compel workplace attention? Most likely because it severely constrains life-giving corporate innovation and change, and inevitably leads to corporate dissolution if not quickly reversed. Complacent companies ultimately face debilitating strategic drift, unplanned obsolescence, and commoditization of their products and services. Complacency is the third to last stage of corporate life: frantic efforts to pull out of the decline is second to last, and the endgame is sudden-death. Internationally renowned dancer Twyla Tharp says, "The same mechanism that protects you from your worst fears can blind you to reality. Denial becomes a liability when you see that something is not working and you refuse to deal with it" (Tharp, 2003). An Ivy League business professor also notes, "With complacency high, transformations usually go nowhere because few people are even interested in working on the change problem" (Kotter, 2012). Numerous companies recently have been tripped-up by complacency and have landed in the business boneyard, including ABG Shipyard, American Airlines, Blockbuster Video, Borders Books, Circuit City, General 
Motors, Gymboree, Hanjin Shipping Company, Kodak, Neiman Marcus, Payless Shoes, Peabody Energy, Reliance Communications, Ltd., Sears, Solyndra, Visa Steel, and Visteon.

\section{Proven Antidotes to Complacency}

Is there any hope for companies already cast adrift in a sea of futurecrippling complacency? There certainly is, and the following are some of the validated methods:

Truthtelling - Innovation and positive change cannot succeed in any organization which does not value and insist on objective truth and candor in all elements of organizational decision-making. Unfortunately, far too many organizations instead utilize aspirational reporting, e.g. shading of the truth or intentional deception. Business strategy scholars note that, "Though business people like to think of themselves as realists, the fact is that wishful thinking, denial, and other forms of avoiding reality are deeply embedded in most corporate cultures" (Bossidy \& Charan, 2004). Because "The first responsibility of a leader is to define reality" (DePree, 2004), corporate truthtelling is a prerequisite to escaping complacency. To thrive as an organization, leaders must deal with reality, speak the truth, and demand the same of every subordinate.

Strategic Guardrails - It is true that, "Members of Great Groups also need relative autonomy, a sine qua non of creativity. No Great Group was ever micromanaged" (Bennis \& Biederman, 1997), and, "In the stream of innovation, many companies make the mistake of building dams instead of doing everything possible to increase the flow" (Kelly, 2001). Leaders must acknowledge that, "It is possible to de-risk bold new strategies through low-cost, low-risk experimentation. Imagination and prudence are not mutually exclusive" (Hamel, 2002). Nonetheless, because all changes and innovations are not equally useful, leaders must decide which strategy best fits the external market situation. The company must "Design for today. If you're trying to lead the market, make sure you're concentrating on a real need. Toyota calls it market-in. Don't confuse an unarticulated need with a nonexistent one" (May, 2007). They must regularly communicate an explicit system that connects strategic corporate priorities, the activities that achieve those priorities, and how the efforts of each employee contribute to the realization of the corporate strategy. The related innovation strategy must be clear, easy to measure and recognized throughout the company with performance-based rewards. A small number (e.g. five to eight) of well-considered metrics is important to doggedly follow and guide this process. Leaders describe the targets and trust employees to find innovative methods to achieve them.

Customer Focus - Customers are the beginning and the end of every corporate success story. Employees at all levels need to leave the office and spend substantially more face-time with customers if they are to achieve fresh, original insights about customer needs: "Increasingly, customers interact deeply with vendors in an interaction that generates new insights and innovation at both the 
product and the process level" (Hagel \& Brown, 2005). In fact, companies will likely need to reach beyond traditional numerical market research and observe first-hand the activities and behaviors of customers in their homes, workplaces, and public environments, often called "empathic research" (Suri, 2005) Heather Fraser of the University of Toronto similarly noted, "If you begin with the user and set out on a path to look at the broader context of their lives and activities, you will suddenly see a whole new set of opportunities to be tapped" (Fraser, 2006). With IDEO researchers, Rodriguez and Jacoby thought: "Ask yourself, what is the biggest risk: placing a bet on a value proposition that customers ask for either latent or direct, or investing in an idea that stems from the cloistered hypotheses of a deep conference hall in your company"

Hire "Wild Ducks" - Since the rise of efficiency expert Frederick Taylor, there has been an unrelenting corporate backlash against innovators. In the current volatile global marketplace, companies must find ways to escape the constraints of industry precedent, tradition, and orthodoxy: "Squashing new ideas because they seem strange, or setting up barriers to protect against the 'disruption' by outside forces, puts the organization at immediate risk of becoming outdated and left behind in the marketplace" (Gryskiewicz, 1999). Non-linear ideas come from non-linear employees. Sutton (2002) mentions that while many organizations would consider extreme diversity to reflect errors and mutations in a system that is designed to do old things in old ways, it is actually the blood of innovation ".

Even the concept of diversity needs to be recast, which, according to Skarzynski \& Gibson, 2008 mentions that diversity in leadership of innovation should include age, race, country of origin, education, sex and other personal characteristics considered essential. In addition to the observable features of the observer, an innovative workforce is composed of people with diverse experience, perspectives and attitudes.

The single most important strategy for enhancing creativity in teams is deliberately building in cross-fertilization by selecting members with a broad range of skills and backgrounds (Gryskiewicz, 1999): "The coming together of different skills and capabilities, attitudes and behaviors generates excitement, new ideas, and new opportunities" (Andrew \& Sirkin, 2006). Identity diversity is but a proxy for requisite cognitive diversity, which provides crucial diverse perspectives and interpretations (Page, 2007). The firm must be forgiving of personal idiosyncrasies exhibited by those who are "different": "Your company must find informed individuals who eschew conventional wisdom and are thinking differently about the business. They may be mavericks who are congenitally unhappy with the direction of the business. They may be talented outliers in the technology department or sales with insights into new customers and technologies that give them an idea for a new business" (Day \& Schoemaker, 2006). To fully leverage as many unique individual capabilities as possible, "It is smart to hire slow learners, to tolerate deviants, heretics, eccentrics, crackpots, weirdos, and just plain original thinkers, even though they will come up with many ideas that are strange mutations, dead ends, and utter failures. The cost is worthwhile because they also generate a large pool of ideas- 
especially novel ideas - than you can get from just hiring and breeding fast learners" (Sutton, 2002). Leadership authority Bennis noted, "But whatever their appearance, they are always rule-busters. People in Great Groups are never insiders or corporate types on the fast track: They are always on their own track" (Bennis \& Biederman, 1997). If new ideas are truly essential to corporate success, hiring "people who make you uncomfortable, even those you don't like, is another way to find a few useful misfits who will ignore and reject the organizational code... Hire people who make you squirm; that's how you get new ideas" (Sutton, 2002).

Learn - New learning is an essential prerequisite for corporate innovation and positive change: "In a healthy innovative company, leadership supports learning and puts in place the systems for it to happen...Driving innovation into the business mentality requires learning and change" (Davila, et al., 2006). In addition, Nonaka (1991) states that putting the personal knowledge at the disposal of others is the central activity of our knowledge-making society. It takes place continuously at all levels of the organization.

Company leaders must create an environment in which information is routinely located, brought inside, cataloged and stored, and distributed to all who can use it. Learning is the mechanism that translates ideas into profitable action. (Junginger, 2007).

Without new learning, our access to "signals" of the future is challenged: "An individual's or organization's inability to recognize the meaning and potential of signals - be they in emerging technologies or emergent behavior - comes from the limits of their rational boundaries" (Manu, 2007). There are major corporate benefits to developing institutional peripheral vision: "Learning to detect weak signals in the distance helps the astute organization to recognize the once unrecognizable.

After Gryskiewicz (1999), learning to detect weak signals remotely helps an organization able to be recognized, once unrecognized. Learning to do this before entering the competition offers a strategic asset that can ensure survival. What is clear is that organizations that consciously decide to adapt to these intermittent and distant signals get critical information much faster than those waiting to get into an orderly and orderly band.

Share - Harvesting new information is only the prelude to creativity and successful innovation: "All Great Groups share information effectively. Many of the leaders we have looked at were brilliant at ensuring that all members of the group had the information they needed" (Bennis \& Biederman, 1997). Leaders must intentionally guide the development of systems that capture appropriate information and disperse it to those who can best use it: "To build capability, participants must capture and disseminate the results of this innovation more broadly within and across enterprises"(Davila, et al., 2006). In brief, "Those who have created knowledge must come to the attention of those who seek knowledge creation, and vice versa (von Krogh, et al., 2000).

To effectively disseminate ideas, new methods for sharing must also be used: "If clarity of vision is key, if seeing is at the heart of success, then the visual 
environment of the innovators is a key success factor" (Davila, et al., 2006). An accurate measurement of progress in learning and innovation in modern organizations is the extent to which non-textual visual representations of concepts and ideas are developed and shared between leadership, employees, and customers. The ability to translate ideas into two- or three-dimensional portrayals of the ideas is an essential competency in innovation. Drawing, computer rendering, clay carving, etc. are just some of the ways of making rapid prototypes: "In their simplest forms, prototypes are spreadsheets, process maps, or simulations - anything simple that enables you to visualize and understand better where your ignorance exists" (Hagel $\&$ Brown, 2005). Cheap, quick, and rough prototypes greatly expand the conversation about possible innovations: "Tell the story with pictures...get graphic about it, literally or figuratively. Get visual: storyboard it, diagram it, mindmap it, whiteboard it, butcher-paper the walls and go crazy" (May, 2007).

Encourage Creative Friction - Successful organizations are rarely sedate, comfortable environments. Instead, by design and through continual leadership prodding, they feature urgency, exhuberance, and engagement by employees, caused by what has been termed creative friction, productive abrasion, and dynamic tension (May, 2007). While not easy to direct, "Dynamic Tension is a term coined here for a strategic mechanism that spurs breakthrough thinking. It's the setting of opposing forces in direct competition or conflict with each other, purposefully creating a Dynamic Tension that demands harmonious resolution" (Hagel \& Brown, 2005). "Creative friction can be very good for an organization: "Properly harnessed, friction can become very productive, accelerating learning, generating innovation, and fostering trust across diverse participants" (Hagel \& Brown, 2005). In addition, "When people with diverse backgrounds, experiences, and skill sets engage with each other on real problems, the exchange usually generates friction - that is, misunderstandings and arguments - before resolution and learning occur. Productive friction requires difficult negotiations among people with very different skills, experiences, and mindsets" (Hagel \& Brown, 2005).

Leaders have important roles to play in the proper development and utilization of friction, as, "Productive friction is most likely to occur when performance requirements are clear, aggressive, and unconstrained" (Hagel \& Brown, 2005). Middle-ground bargaining is not useful: "Hirshberg (1998) mentions that "instead of trying to reduce the friction that occurs naturally between people who collaborate together by diluting or compromising positions, creative abrasion is needed to develop leadership styles that focus on identifying and incorporating points polarized view ".

In summary, "Perhaps we should learn to embrace friction, even to seek it out and to encourage it, when it promises to provide opportunities for learning and capacity building. We need institutional frameworks that can help foster productive friction and the learning that comes with it" (Hagel \& Brown, 2005).

Encourage Appropriate Failure - Sadly, "Most companies penalize failure" (Schwartz, 2004), yet regular and methodical failure is crucial to eventual innovation success. It is essential for leaders to signal the propriety of failure and to 
clearly distinguish between "good failure" and "bad failure." In brief, "bad failure" is that which is repeated and nothing new is learned from it. "Good failure" happens often, but the same event is not repeated because something is learned from it, duly recorded, and disseminated to others in the organization. Increasing the number of successful innovation tries is simply a function of exponential growth in the right kind of failures" (Davila, et al., 2006). Leadership must provide "air cover" for employees so they are not sanctioned for appropriate failure.

Small, rapid, inexpensive experiments are part and parcel of risk reduction and successful innovation: "Organizations need to create an environment where taking risks on breakthrough innovations is recognized as valuable to the company... in order to achieve truly valuable breakthroughs in the long term; it is necessary to accept (and learn from) failures in the short term" (Davila, et al., 2006). In innovative companies, "Failure is the rule rather than the exception, and every failure contains information...failure is what moves you forward. Listen to failure" (Schwartz, 2004). Only by encouraging failure can positive advancement occur: "To think creatively is to walk at the edge of chaos. In thinking the original, we risk thinking the ridiculous. In opening the way for a few good ideas, we open the way for many bad ones, lopsided equations, false syllogisms, and pure nonsense dished up by unhindered impulse (Grudin, 1990). Small, rapid, and inexpensive experiments mitigate risk from corporate innovation.

\section{Conclusion}

Employee disengagement fueled by complacency can lead to corporate failure, regardless of the size or legacy of the enterprise. While many issues cause complacency, making some specific systemic changes can result in increased creativity, engagement, and innovation. Leaders deciding whether combating complacency is worth their efforts need only realize that they are not only responsible for today's success but also that there will be a corporate tomorrow.

\section{References}

Andrew, J., \& Sirkin, H. (2006). Payback: Reaping the rewards of innovation. Boston: Harvard Business School Press.

Bennis, W. \& Biederman, P. (1997). Organizing genius. New York: AddisonWesley.

Bossidy, L., and Charan, R. (2004). Confronting reality. New York: Crown Business.

Davila, T., Epstein, M., \& Shelton, R. (2006). Making innovation work. Upper Saddle River, NJ: Wharton School Publishing.

Day, G., and Schoemaker, P. (2006). Peripheral vision. Boston: Harvard Business Review Press.

DePree, M. (2004). Leadership is an art. New York: Crown Business.

Fraser, H. (2006). Turning design thinking into design doing, Rotman Magazine, Spring/Summer, 24-28. 
Gray, D. (2014). The connected company. Sebastopol, CA: O'Reilly Media. Grudin, R. (1990). The grace of great things. New York: Ticknor \& Fields. Gryskiewicz, S. (1999). Positive turbulence. San Francisco: Jossey-Bass.

Hagel, J. \& Brown, J. (2005). The only sustainable edge. Boston: Harvard Business School Press.

Hamel, G. (2002). Leading the revolution. New York: Plume.

Hirshberg, J. (1998). The creative priority. New York: Harper Business.

Junginger, S. (2007). Learning to design: giving purpose to heart, hand and mind, Journal of Business Strategy, 28(4), 59-65.

Kawasaki, G. (1999). Rules for revolutionaries. New York: HarperCollins.

Kelley, T. (2001). The art of innovation. New York: Currency Doubleday.

Kotter, J. (2012). Leading change. Boston: Harvard Business Review Press

Manu, A. (2007). The imagination challenge. Berkeley, CA: New Riders.

May, M. (2007). The elegant solution. New York: Free Press.

Nonaka, I. (1991). The knowledge-creating company, Harvard Business Review 69(6), 96-104.

Page, S. (2007). The difference. Princeton, NJ: Princeton University Press.

Rodriguez, D., \& Jacoby, R. (2007). Innovation, growth, and getting where you want to go, Design Management Review, 18 (1), 10-15.

Schwartz, E. (2004). Juice: The creative fuel that drives world-class inventors. Boston: Harvard Business School Press.

Slater, R. (2004). Jack Welch on leadership. New York: McGraw-Hill.

Suri, J. (2005). Thoughtless acts? San Francisco: Chronicle Books.

Sutton, R. (2002). Weird ideas that work. New York: Free Press.

Tharp, T. (2003). The creative habit. New York: Simon and Schuster.

von Krogh, G., Ichijo, K., \& Nonaka, I. (2000). Enabling knowledge creation. Oxford, UK: Oxford Press. 